\title{
Del yo al nosotras y de lo personal a lo político: La construcción de la conciencia de género en talleres para mujeres ${ }^{1}$
}

\author{
From Me to Us and from the Personal to the Political: \\ Building Gender Awareness in Workshops for Women
}

BÁRBARA CATALINA LÓPEZ CASTILLO

Universidad Austral de Chile

RECEPCIÓN: 28/09/20I6• ACEPTACIÓN: 03/I 2/20I 6

\begin{abstract}
RESUMEN El estudio realiza un análisis sobre un conjunto de actividades pedagógicas con financiamiento estatal, orientadas a mujeres consideradas vulnerables, que promueven concienciación de género al abordar temáticas como ejercicio de derechos, participación política y social y otras materias vinculadas al empoderamiento femenino. Se trata de los Talleres para $\mathrm{Mu}$ jeres, ejecutados por la Fundación para la Promoción y Desarrollo de la Mujer (Prodemu) y, específicamente, del Taller de Desarrollo Personal del sector Pishuinco, en la comuna de Valdivia, realizado entre abril y junio de 20I 5. Fundada en una metodología etnográfica, esta pesquisa se sirve de la antropología del género, la educación popular y la pedagogía feminista, e incorpora reflexiones que abarcan desde el feminismo de la segunda ola hasta el feminismo poscolonial para problematizar la experiencia que describe, destacando las potencialidades de los procesos colectivos de concienciación,
\end{abstract}

I. Proyecto de Titulación «Puertas cerradas, puertas abiertas: El proceso de concienciación de género en los Talleres para Mujeres de la Fundación Prodemu, Valdivia, Región de Los Ríos». Universidad Austral de Chile, 2016. 
y a la vez poniendo en tela de juicio el fenómeno mismo de la construcción de conciencia de género.

PALABRAS CLAVE Concienciación de género, talleres, mujeres.

ABSTRACT The study analyzes on a set of state-funded pedagogical activities aimed at women as vulnerable, promoting gender consciousness in addressing issues such as excercise of rights, political an social participation an other matters related to woman's empowerment. There are «Talleres para Mujeres» («Workshops for Women»), administered by the Fundación para la Promoción y Desarrollo de la Mujer (Foundation for the Promotion and Development of Women, Prodemu), and specifically the «Taller de Desarrollo Personal» («Personal Development Workshop») of Pishuinco sector in the Commune of Valdivia, between April and June of 201 5. Founded in ethnographic methodology, this research uses anthropology of gender, popular education and feminist pedagogy, and incorporates reflections ranging from feminism of the second wave to the post-colonial feminism to problematize the experience described, highlighting the potential of collective processes consciousness, while putting question the phenomenon of gender consciousness building itself.

KEYWORDS Gender consciousness, workshops, women.

\section{Introducción}

La Fundación para la Promoción y Desarrollo de la Mujer es una institución de derecho privado, sin fines de lucro, y es parte de la Red de Fundaciones de la Dirección Sociocultural de la Presidencia. Su quehacer se concentra en dos áreas. En primer lugar, en el Área de Autonomía Económica que «promueve el desarrollo de competencias personales y técnicas, para la plena autonomía económica de las mujeres a través de diferentes programas [...]: Capacitación para el Empleo, Mejorando mi Negocio, Formación y Capacitación para Mujeres Campesinas y Desarrollo de Competencias Laborales». ${ }^{2} \mathrm{Y}$, en segundo lugar,

2. Referencias obtenidas de folletería de la Fundación entregada en Jornada de Difusión en el marco de la conmemoración del Día Internacional de la Mujer. Plaza de la República de la Ciudad de Valdivia, 9 de marzo de 20 r 5. 
en el Área de Promoción y Desarrollo de la Mujer, que «entrega a las mujeres información sobre sus derechos, herramientas para el ejercicio del liderazgo y apoyo a sus organizaciones, a través de jornadas informativas, campañas públicas de difusión de derechos, talleres que promueven el desarrollo personal, asesoría a organizaciones comunitarias, un fondo de apoyo a organizaciones y escuelas de líderes».

Los Talleres para Mujeres se enmarcan en la última área y son definidos por Prodemu como una iniciativa de educación no formal, «que se articula y retroalimenta a partir de la integración de los enfoques de la pedagogía de género, la educación popular, el constructivismo y las metodologías de educación para adultos/as». ${ }^{3}$ Están pensados para grupos de veinte mujeres que tengan en común un territorio y/o agrupación, con interés en una instancia de aprendizaje colectivo que tiene por objetivo «aportar al desarrollo de un proceso de dos fases que se articulan entre sí: a la construcción de las mujeres como sujetos de derechos y la ruptura de la desigualdad de género». Así, de la mano de una dupla compuesta por una funcionaria estable de la Fundación y una monitora externa, se realizan seis sesiones obligatorias que fundamentalmente intentan promover conciencia sobre de las desigualdades sociales entre hombres y mujeres, estimular la participación social mediante grupos de mujeres, trabajar la autoestima personal mediante la valorización del tiempo propio y la toma de decisiones; e informar sobre derechos humanos y en particular sobre derechos sexuales y reproductivos. Opcionalmente, se realizan hasta cuatro sesiones complementarias para profundizar los mismos contenidos, según las necesidades que el grupo manifieste o que las monitoras identifiquen. ${ }^{4}$

Los Talleres para Mujeres congregan varios argumentos de cuestionamiento de la sociedad patriarcal dentro de los estrechos márgenes de la institucionalidad de género chilena. La dinámica de trabajo que proponen remite a los grupos de concienciación del feminismo de la segunda ola descritos por Catharine MacKinnon (I995), y a su vez se alinea con una perspectiva de género y un enfoque de derechos estrechamente ligados al Estado. Esta instancia, que desde sus fundamentos descritos busca promover socialización, empoderamiento y aprendizaje grupales, impulsa así un conjunto de procesos que pueden va-

3. Extraído del documento "Características del enfoque metodológico aplicado a los procesos formativos de las mujeres 20I5", de la Fundación Prodemu.

4. Síntesis de lo descrito en el documento «Características del enfoque metodológico aplicado a los procesos formativos de las Mujeres 201 5", de Fundación PRODEMU. 
riar según los intereses, contexto, capacidades y voluntades de sus implicadas; elementos a los que difícilmente las ejecutoras pueden adelantarse. Así, por ejemplo, en la aplicación de la perspectiva institucional de género influye el nivel de profesionalización, conocimiento y experiencia de las facilitadoras de los talleres, su grado de apego a la misión y visión de Prodemu, entre otros factores. Por su parte, el grupo objetivo de mujeres se relaciona de múltiples maneras con la propuesta y tiene diversas experiencias en torno a ella, evidenciando la compleja interacción que se produce entre la línea de trabajo y quienes la reciben en calidad de participantes del taller.

La presente investigación describe las experiencias de las mujeres involucradas en el Taller de Desarrollo Personal de Pishuinco, a través de una etnografía de las prácticas e interacciones, y fundamentalmente por medio de las voces de las protagonistas del proceso, analizando tanto el decurso y los resultados de la iniciativa, como las relaciones generadas a en torno a la misma.

\section{Marco teórico}

\section{Las identidades femeninas al alero del Estado}

El reconocimiento y la visibilización de la existencia del binarismo hombremujer como una relación asimétrica que permea todas las estructuras de la sociedad occidental, ha sido producto de la acción de los grupos feministas, los movimientos por la diversidad sexual, las convenciones internacionales en torno al género y los acuerdos que se han tomado a partir de ellas, entre otros factores (Cook, I993). Así, se puede concluir que existe un devenir histórico del concepto género que posee un proceso de posicionamiento e institucionalización en los gobiernos de las últimas décadas, fundado en el enfoque de derechos y productor de políticas públicas diferenciadas para grupos de mujeres, basadas en las evidencias de desigualdad social entre los géneros:

Pese a los intentos por superar las demarcaciones de lo femenino y masculino [...], las categorías hombre y mujer siguen siendo el locus de relaciones de poder que operan como espejo y reflejo de relaciones políticas, económicas y simbólicas que asignan un estatus y una valoración diferencial a lo femenino y a lo masculino erigiendo así un andamiaje de desigualdades que se expresará en las diversas esferas en las que se construyen las subjetividades y las prácticas de los sujetos (Montecino, 20I4: 209). 
A partir de ello, el Estado, en tanto producto y productor de la cultura (Barragán y Wanderley, 2009), determina uno o varios modelos identitarios del ser mujer que se expresan en las políticas que instaura. Y también, las identidades femeninas son condicionantes de la posición social y la experiencia de las mujeres, producidas y reproducidas por ellas mismas (Riquer, I992). Reconocer al Estado y las mujeres como productores de identidad coadyuva, en un primer paso, a la profundización en las experiencias personales de quienes participaron del Taller de Desarrollo Personal, denotando procesos de concienciación colectiva e individual con límites difusos, y avanzando hacia la reflexión sobre la incidencia del taller en la construcción de dicha conciencia. Como argumenta Florinda Riquer:

El análisis de la experiencia de vida de un conjunto de mujeres permite extraer los aspectos recurrentes de dicha experiencia, como configuración de una identidad social; $\mathrm{y}$ a la vez hace posible rescatar las formas singulares en que esta identidad es expresada por cada mujer [...]. Cada mujer tiene algún tipo de conciencia (psicológica), es decir, autoconocimiento de sí, de otros sujetos y del mundo social en el que habita [...]. Al haber conciencia de sí, de otros y del mundo social [...] la mujer existe, es decir, tiene un «yo soy» que nos abre la puerta a cómo es ese yo [...]. Esto es, ir más allá de su identidad ligada a los atributos y capacidades asignados socialmente al género femenino, para descubrirla en su «para-sí» (Riquer, I992: 62).

Elementos para comprender las relaciones al interior de grupos de mujeres: Enemistad, sororidad, esencialización

Las relaciones entre mujeres están condicionadas por una serie de estructuras entre las que destaca la ideología de la feminidad, un conjunto de ideas que crea y recrea la enemistad histórica de las mujeres (Lagarde, I992), basándose en la competencia por cumplir con los cánones determinados por la estructura patriarcal. Como respuesta a la enemistad histórica y dentro de las claves de la ideología feminista, se establece como salida la construcción de relaciones de sororidad fundadas en el reconocimiento de la subordinación compartida, en detrimento de las rivalidades propuestas por el patriarcado, lo que:

implica la amistad entre quienes han sido creadas por el mundo patriarcal como enemigas. La alianza de las mujeres en el compromiso es tan 
importante como la lucha contra otros fenómenos de la opresión y por crear espacios en que las mujeres puedan desplegar nuevas posibilidades de vida (Lagarde, I992: I8).

Las nociones de esencialización cultural y esencialización de género también son un aporte en el conocimiento y desentrañamiento de relaciones entre mujeres, como crítica al corpus teórico feminista que escinde mujeres privilegiadas y no privilegiadas según se ubiquen en Occidente y/o en el Tercer Mundo, omitiendo las complejidades asociadas a los contextos geopolíticos, de clase, etarios, etcétera, como constitutivos de la realidad de las mismas (Narayan, 2000).

Esta mujer promedio del Tercer Mundo lleva una vida esencialmente truncada, basada en su género femenino (léase: sexualmente constreñida) y su ser del «Tercer Mundo» (léase: ignorante, pobre, sin educación, atada a la tradición, doméstica, orientada a la familia, victimizada, etcétera) Esto, sugiero, está en contraste con la (implícita) representación de sí mismas de las mujeres occidentales como educadas, modernas, que tienen control sobre sus propios cuerpos y sexualidades, y libertad para tomar sus propias decisiones (Mohanty, I99I: 56, en Narayan, 2000: 85; la traducción es nuestra).

Dicha afrenta denunciada por el feminismo poscolonial se manifiesta tanto en el campo académico como en las políticas públicas de género, y se expresa en las prácticas cotidianas de interacción entre mujeres que viven realidades distintas, sea desde aquellas que se consideran privilegiadas hacia quienes consideran oprimidas, y viceversa. Las múltiples posibilidades de relaciones entre mujeres que se describen y analizan en los marcos del Taller para Mujeres resultan ser un aporte para el feminismo actual, dado que:

la importancia de la dialéctica entre la feminidad, el feminismo y las mujeres, tiene como base una preocupación filosófica y política central en el feminismo contemporáneo: la necesidad de conocer de manera crítica la identidad de la mujer y las identidades de las mujeres con un sentido. Se trata de contribuir de manera consciente a la construcción del sujeto mujer, a la transformación de las mujeres en sujetos que se vinculan con otros sujetos en la construcción de la sociedad y de la cultura (Lagarde, I992: 5). 
Educación popular, pedagogía feminista y creación de conciencia: Hacia la práctica de la libertad

La educación popular remite al trabajo del pedagogo brasileño Paulo Freire, quien teoriza sus experiencias de educación y alfabetización con campesinos y trabajadores, iniciadas en Brasil y Chile. Su pedagogía comprende la necesidad de superar la opresión por los propios medios de las masas populares, a través de sus propios procesos de concientización sobre la realidad en que viven, mediados por el diálogo y la experiencia. Esta práctica, orientada hacia la liberación, promueve una conciencia de clase, histórica y política que invita a la acción consciente y organizada.

Al defender el esfuerzo permanente de reflexión de los oprimidos sobre sus condiciones concretas, no estamos pretendiendo llevar a cabo un juego meramente intelectual. Por el contrario estamos convencidos de que la reflexión, si es verdadera reflexión, conduce a la práctica. Por otro lado, si es momento de la acción, ésta se hará praxis auténtica si el saber que de ella resulta se hace objeto de reflexión crítica. Es en ese sentido que la praxis constituye la razón nueva de la conciencia oprimida y de la revolución (Freire, 2003: 62).

El enfoque de educación popular fue reformulado desde la publicación de La pedagogía del oprimido (2003), en buena parte gracias a críticas de mujeres, reconocidas por Paulo Freire:

Al discutir la opresión y la liberación, al criticar con justa indignación las estructuras opresoras, yo usaba sin embargo un lenguaje machista, y por lo tanto discriminatorio, en el que no había lugar para las mujeres. Casi todas las que me escribieron citaban un pasaje u otro del libro, como por ejemplo el que ahora escojo yo mismo: «De esta manera, profundizando la toma de conciencia de la situación, los hombres se 'apropian' de ella como realidad histórica y, como tal, capaz de ser transformada por ellos». Y me preguntaban: «¿Por qué no las mujeres también?» (2005: 88).

En concordancia con los fundamentos de la educación popular, la pedagogía feminista es un conocimiento situado (Haraway, I995; Pérez Bustos, 20 I0) que agrega una reflexión contra el androcentrismo a la lucha por la liberación de oprimidos y oprimidas mediante procesos educativos.

La pedagogía feminista es un conjunto de discursos, una práctica política, y es también una manera específica de educar. Su especificidad consiste en echar una nueva mirada a propuestas político-pedagógicas emancipadoras y desde 
una postura ética, filosófica y política denunciar su parcialidad y su androcentrismo, posicionándose críticamente ante el poder y la dominación masculinos, y promoviendo la libertad y el fortalecimiento de las mujeres, para construir de manera colectiva una sociedad más libre y democrática (Maceira, 2007: 2).

En esa misma línea, la creación de la conciencia es la metodología feminista por excelencia. En ella se busca que las mujeres, mediante procesos grupales, descubran que comparten una realidad en función de su género, comprendiendo las distintas formas de opresión individual y colectiva. Es «la reconstrucción crítica y colectiva del significado de la experiencia social de las mujeres, tal y como la viven las mujeres» (MacKinnon, I995: I 55 ). Así,

crear la conciencia [...] indaga en una situación intrínsecamente social, en esa mezcla de pensamiento y materialidad que comprende el género en su sentido más amplio [...]. La creación de la conciencia es el proceso a través del cual el análisis feminista radical contemporáneo de la situación de las mujeres toma forma y se comparte (MacKinnon, I995: I 56).

Esta metodología se imbrica con el entendimiento de la realidad que describe la educación popular, como síntesis entre subjetividad y objetividad (Freire, 2005). Con la pedagogía feminista la comunicación es igualmente estrecha, pues ambas reconocen la particularidad de la experiencia social femenina en escenarios construidos androcéntricamente, abogando por una epistemología distinta (MacKinnon, I995), una forma de conocer situada desde la mirada de las mujeres, que sobrepasa los límites convencionales del conocimiento científico. La relación entre la práctica pedagógica feminista y la validación de ésta como otra forma de conocimiento se explica porque «la transgresión es un movimiento contra y más allá de las fronteras, más allá de los límites, que hace a la educación una práctica liberadora [...]. La transgresión —dice Marcela Lagarde- inaugura paradigma» (Maceira, 2007: 3-4).

\section{Metodología}

\section{Método etnográfico}

La etnografía define a esta pesquisa pues articula analíticamente un intenso trabajo de campo en las sesiones del Taller de Desarrollo Personal, enfatizando en la experiencia social de las involucradas, recurriendo a diversas formas de recolección de datos y realizando un posterior análisis interpretativo que se 
empeña en describir y comprender lo estudiado. Aunque la definición de etnografía suscita una extensa reflexión, sintéticamente es «una propuesta descriptiva en la que el investigador intenta ser fiel a la hora de describir e interpretar la naturaleza del discurso social de un grupo de personas» (Wilcox, I993: 96). Además, «en tanto enfoque, constituye una concepción y práctica de conocimiento que busca comprender los fenómenos sociales desde la perspectiva de sus miembros» (Gúber, 20II: I6). En tanto método, le subyace el diseño flexible de investigación, ampliamente trabajado en ciencias sociales aunque desde diversas posturas (Bassi en Canales, 20I3; Mendizábal en Vasilachis de Gialdino, 2006).

Este trabajo se nutre particularmente del enfoque etnográfico de la etnografía escolar o de aula:

Aunque la etnografía se ha considerado tradicionalmente como la descripción de la cultura de toda una comunidad, ha sido y es igualmente aplicable a la descripción del discurso social en cualquier grupo de personas entre las cuales las relaciones sociales están reguladas por la costumbre. Las aulas y colegios se adaptan bien a la investigación etnográfica aunque la diferencia de enfoque y ámbito requiere ciertas variaciones (Wilcox, 1993: 96).

Dado que el Taller de Desarrollo Personal en Pishuinco se origina en un marco gubernamental, una variación necesaria está en la incorporación de la etnografía del Estado, que reconoce que «la antropología permite concebir al Estado como un producto cultural y no sólo como productor de cultura [...], observando que el Estado se produce en prácticas cotidianas, en encuentros, en representaciones y performances culturales» (Barragán y Wanderley, 2009: 2I).

\section{Entrevista en profundidad enfocada}

La observación participante — piedra angular de la etnografía realizadaabrió puertas para realizar entrevistas, donde «de los investigadores se espera captar y acceder a una información verbal oral que exprese las maneras de ver, pensar y sentir de los propios entrevistados que participan de esta interacción regulada por preguntas abiertas y respuestas libres» (Gaínza en Canales, 2006: 22I), siendo la manera idónea de recoger las experiencias de las participantes 
del taller, a través de sus voces y propias palabras. De allí deriva el uso de la entrevista en profundidad enfocada, "destinada a abordar la experiencia de un sujeto expuesto a una situación o acontecimiento temporalmente delimitado» (Gaínza en Canales, 2006: 254), modalidad adecuada para abordar lo referido a los talleres.

Las entrevistas fueron realizadas en los domicilios de las mujeres y en el aula utilizada para las actividades del Taller de Desarrollo Personal, y se consiguieron solicitándolas a las participantes con quienes hubo mayor construcción de confianza durante el proceso de observación participante, y a aquellas que se destacaron por su involucramiento activo y elocuencia a lo largo de las sesiones del taller. Se consiguieron siete entrevistas de las cuales cinco son exhibidas mediante fragmentos en los resultados de la pesquisa. Respecto a las funcionarias de Prodemu - directora provincial, facilitadora estable y monitora externa-, sus entrevistas se realizaron en traslados al territorio de Pishuinco y en la oficina de la Fundación. El grado de rapport no fue condicionante para la concreción de estas entrevistas ya que previamente la Dirección Provincial de la Fundación solicitó al equipo colaborar en todas las actividades requeridas para este trabajo.

\section{Estrategias de análisis}

Basada en el enfoque de educación popular, donde se promueve la horizontalidad de la relación educador-educando sin perjuicio de la posición respectiva de cada involucrado/a en el proceso formativo (Freire, 2003), esta pesquisa determinó categorías de análisis que pudieran ser igualmente aplicables para las declaraciones y prácticas de facilitadoras y participantes, unificándolas ante su condición de mujeres y su situación de educadoras-educandas en el taller. Así, las declaraciones se valorizaron como negativas, positivas o balanceadas, según refirieran a expectativas o relaciones relativas al taller. Por su parte, la categoría de concienciación de género al interior del taller propició el surgimiento de definiciones personales sobre concienciación de género y relatos de vivencias propias al respecto, dos categorías emergentes en términos de análisis de la información recogida. 


\section{Resultados}

\section{Expectativas}

Indagar en las expectativas de las ejecutoras y participantes del Taller de Desarrollo Personal permitió visibilizar el punto de partida del proceso formativo, lugar desde donde cada una de estas mujeres inició y se posicionó ante dicha instancia. Este apartado se fundamenta en que:

No podemos dejar de lado, despreciado como inservible, lo que los educandos [...] traen consigo de comprensión del mundo, en las más variadas dimensiones de su práctica dentro de la práctica social de que forman parte [...]. SLa localidad de los educandos es el punto de partida para el conocimiento que se van creando del mundo. «Su» mundo, en última instancia, es el primer e inevitable rostro del mundo mismo (Freire, 2005: $8 \mathrm{I}-82)$.

Así, la posición previa de participantes y ejecutoras incide en cómo concibe cada una no sólo su propia realidad, sino la realidad de la otra al momento en que éstas se intersectan en el taller. De allí derivan sesgos, prejuicios, expectativas erradas o acertadas, etcétera, todo lo cual influye en las relaciones generadas y el trabajo realizado.

La mayoría de las expectativas de las involucradas en el taller fueron positivas, presentándose algunos matices a considerar. Las funcionarias y la monitora externa esperaban que las participantes pudieran trabajar el reconocimiento personal, ejercitar la participación, involucrarse en su entorno social y desarrollar habilidades y capacidades a lo largo del taller. Sus expectativas más negativas guardaron relación con la efectividad del trabajo a realizar, que les pareció plausible a mediano o largo plazo. Para ellas, la intangibilidad y abstracción de los resultados que se les ofrecen - la posibilidad de aumentar su conciencia de género, autonomía, conocimiento de derechos, etcétera- dificulta que la propuesta del taller cobre sentido para las mujeres inmediatamente, arguyendo que la mayoría busca capacitarse laboralmente o recurre a iniciativas de apoyo monetario o insumos al momento de inscribirse en cursos y talleres.

Con esta área, fortaleciendo el desarrollo personal, poniendo temas de contingencia, como es el tema de la sexualidad, de la violencia contra la mujer... [...]. Que las mujeres entiendan eso me hace mucho sentido, [...] 
pero yo sé que no va a ser... a lo mejor es un cambio o un resultado, yo espero, a mediano plazo. No va a ser al corto plazo [...]. Y no van a poder ser a corto plazo porque tienes que encontrar la fórmula perfecta de que esta área les haga sentido a las mujeres con las que nosotras trabajamos (directora provincial Fundación Prodemu).

Desde la pedagogía feminista, todas las involucradas en los procesos formativos, independientemente de su posición y clase, experimentan diversas formas de desigualdad de género, por lo que «[intentan] cuestionar colectivamente el papel que juega la cultura en la formación de una matriz generadora de comportamientos, hábitos, lenguajes, valores y relaciones sociales opresivas» (Korol, 2007: 4), a sabiendas de que esa matriz cultural involucra a todas las mujeres y también a todos los hombres. Esta premisa guarda relación con otro axioma de la educación popular, dialógica y problematizadora, donde «el diálogo, como encuentro de los hombres [y mujeres] $]^{5}$ para la tarea común de saber y actuar, se rompe si sus polos (o uno de ellos) pierde la humildad. ¿Cómo puedo dialogar, si alieno la ignorancia, esto es, si la veo siempre en el otro, nunca en mí?» (Freire, 2003: 103).

No obstante, el lenguaje de las dos facilitadoras del grupo denotó la verticalidad con la que llevaron a cabo el trabajo del Taller:

Mis expectativas, para el grupo que tenemos acá... yo espero que se produzca un cambio... personal, y también colectivo, de ellas. Porque la expectativa que ellas tienen es formar una agrupación de mujeres [...] Esas son, yo creo que mis mayores expectativas, de dejarlas como conformadas como agrupación de mujeres... (facilitadora estable Fundación Prodemu).

Darle como el punch a las mujeres de que pueden salir adelante, de que si bien es cierto [...] no han tenido las mismas oportunidades que uno ha tenido, en la vida se puede salir adelante... (monitora externa Fundación Prodemu).

Las declaraciones de esa índole también se expresaron en las prácticas pedagógicas, altamente vinculadas a la lógica de la educación bancaria, observándose entonces la dificultad de quienes ocupan el rol de educadoras de no

5. Recordar el uso del lenguaje con sesgo machista en las primeras obras de Freire, el cual se refutara a sí mismo más adelante. De allí la inclusión de «[las mujeres]». 
reconocerse también educandas y también subordinadas por su condición de género; lo que redunda en la distancia establecida entre los dos grupos de actoras y que justifica la labor de depositar saberes y conocimiento en aquellas que no los poseen. Una educación problematizadora, por el contrario, implica que:

el acercamiento a las masas populares se haga, no para llevar un mensaje «salvador», en forma de contenido que ha de ser depositado, sino para conocer, dialogando con ellas, no sólo la objetividad en que se encuentran, sino la conciencia que de esta objetividad estén teniendo (Freire, 2003: I07).

En cuanto a las participantes, algunas manifestaron no estar convencidas de asistir al taller en primera instancia. Esto lo atribuyen a las convocatorias, donde la intangibilidad de la propuesta y el énfasis en el «factor sorpresa» de las actividades dificultó su compresión, tal como sospechaban las ejecutoras.

La primera vez que vino ella, vino a darnos un discurso... pero no dijo ella de qué se trataba el taller ¿cachái? Dijo de que iban las sorpresas. Claro, uno igual queda como intrigada po. Claro, nosotras decíamos, uy, capaz qué cosa iremos a hacer (Silvina, 23 años).

A mí me dijeron que vaya, que iba a haber un taller no más, no para mujeres. Me dijeron que vaya a ver para ver de qué se trataba, y fui no más, y me gustó después. Pero nunca me dijeron que no, que esto era de la mujer, que iba a ser de esto, o de esto otro... (Carla, 22 años).

No obstante, otras mujeres tenían muchas expectativas positivas ante la oportunidad de socializar fuera de sus hogares, hablar e informarse sobre temas específicamente dirigidos a mujeres y trabajar sus habilidades personales como autoestima, autoconocimiento u otras - lo que denominaron varias veces como «apoyo sicológico»-, distinto de las capacitaciones o cursos que normalmente ofrecían en el sector, relativas a oficios, manualidades, etcétera.

Acá siempre hacen talleres y cuestiones así y yo nunca me inscribo en nada entonces era como pa probar no más [...]. Sí, como oficios... eso por el Sence. Y nunca nadie lo había terminado, en cambio ahora es entretenido el taller. No son como los otros talleres que son fomes (Selena, 22 años). 
Cuando me inscribí esperaba informarme más, porque yo siempre soy bien como de informarme, incluso como cuando hablamos hoy de los temas de los abortos [...]. Yo siempre me estoy informando, que busco en Google cualquier cosa de repente. Y veo cosas de las mujeres en la tele, cosas de La Jueza... entonces siempre me estoy informando. A mí me gusta estar así, informada, a ver qué cosas nuevas hay que uno puede postular o qué se yo (Carla, 22 años).

Lo anterior representa la tensión entre la aceptación y el rechazo de la tradición asistencialista forjada por la institucionalización de las agrupaciones de mujeres en la historia reciente de Chile:

CEMA-Chile y la Secretaría Nacional de la Mujer no se recrean para producir las condiciones de autodesarrollo para las mujeres o para otorgarles una cuota de poder real en términos de participación social. Más bien, la Secretaría Nacional de la Mujer organiza y realiza cursos que son necesarios para formar a las mujeres que va a ser capacitadoras de las «madrecitas» (las mujeres de sectores populares). CEMA-Chile provee los espacios para que este proceso se lleve a cabo (Weinstein, I996: I2).

La propuesta de Talleres para Mujeres es recibida con desconfianza pues no parece mostrar apoyo material, económico o tangible; o bien es acogida con interés por enfocarse en áreas que las mujeres perciben como relegadas tanto por ellas mismas como por los organismos que se les acercan. La tradición a la que responde esta situación se remonta a lo ocurrido con CEMA Chile durante la dictadura militar, cuando funcionó más claramente como organismo disciplinador de la organización femenina.

\section{Relaciones}

Durante las sesiones del taller y a simple vista, se pudo observar a una dupla de facilitadoras interactuando con un grupo de mujeres en una sala, sin embargo las formas de relación entre ellas fueron múltiples. Desde la educación popular, las relaciones entre quienes están en un proceso educativo se fundan en el diálogo, pues éste a su vez media la relación entre la conciencia y el mundo que permite conocer, educarse (Freire, 2003). En la relación dialógica, educador/a y educando/a, cada uno y cada una en ese doble rol, construyen conocimiento conjunto incluso desde sus distintas posiciones: 
El diálogo entre profesoras o profesores y alumnos o alumnas no los convierte en iguales, pero marca la posición democrática entre ellos o ellas [...]. El diálogo gana significado precisamente porque los sujetos dialógicos no sólo conservan su identidad, sino que la defienden y así crecen uno con el otro. Por lo mismo, el diálogo no nivela, no reduce el uno al otro [...]. Implica, por el contrario, un respeto fundamental de los sujetos involucrados en él que el autoritarismo rompe o impide que se constituya [...]. La relación dialógica no anula, como se piensa a veces, la posibilidad del acto de enseñar. Por el contrario, funda ese acto, que se completa y se sella en el otro, el de aprender, y ambos sólo se vuelven verdaderamente posibles cuando el pensamiento crítico, inquieto, del educador o de la educadora no frena la capacidad del educando de pensar o comenzar a pensar críticamente también (Freire, 2005: II2-II3).

En ese sentido, las relaciones del taller, aunque mediadas por la palabra, no necesariamente son relaciones dialógicas. Esto debido a la dinámica mecanicista y rígida de las prácticas pedagógicas, separadas por módulos, sesiones y actividades debidamente delimitadas, que dificultan el diálogo horizontal y la reflexión acabada; y por las expectativas ya revisadas de sus involucradas, que suponen desde antes una distancia entre mujeres que enseñan, por un lado, y mujeres que aprenden, por el otro.

Las participantes declararon haberse relacionado positivamente con las monitoras, considerándolas abiertas a la resolución de dudas frente a las temáticas tratadas y al acompañamiento en las actividades. Las describieron como cariñosas, afectivas y dedicadas en su manera de explicar los contenidos abordados. Sin embargo, algunas se quejaron del uso de un lenguaje demasiado complejo por parte de la monitora externa, con términos y conceptos desconocidos que entorpecían la comprensión de sus enunciados. En ese sentido:

Si el educador [o educadora] no se expone por entero a la cultura popular, difícilmente su discurso tendrá más oyentes que él mismo [o ella misma]. Más que perderse inoperante, su discurso puede llegar a reforzar la dependencia popular, puede subrayar la conocida «superioridad lingüística» de las clases dominantes (Freire, 2005: IO2).

Así, se explican las declaraciones de la monitora externa, quien se mostró agradecida de la experiencia laboral en el taller y con «las usuarias», sin referir 
mayormente al nexo con ellas, notablemente influido por la distancia que su lenguaje demarcó respecto de sus interlocutoras. La funcionaria estable, por su parte, definió su relación con las mujeres desde de la voluntad de orientarlas y apoyarlas permanentemente, aunque siempre a partir del interés inicial del grupo de mujeres, destacando la imposibilidad de forzar dicha relación sino basándola en el ahínco de ellas.

Las distintas relaciones hasta aquí descritas y referidas por las entrevistadas comparten el influjo de la enemistad histórica (Lagarde, I992: 3), una tendencia de relaciones femeninas que distancia a las mujeres unas de otras a partir de criterios como prestigio, clase, etnia u otros; todos definidos desde cánones de pensamiento androcéntrico. Marcela Lagarde revela que «es tal la enajenación, que la separación entre yo y la otra se convierte en distanciamiento, en desconocimiento, de aquello que compartimos como condición genérica, así como de lo específico: desconocemos también mi yo en la otra, y su yo en mí» (I992: 3). Esta situación, sumada a la esencialización implícita de la identidad del grupo de mujeres en oposición a la identidad de las facilitadoras, explica por qué estas últimas se relacionan desde el cariño asistencialista con las participantes, quienes las perciben como fuentes de consulta y consejo, superiores en conocimiento y experiencia.

En realidad en los grupos más vulnerables, les cambia la vida... ¡les cambia la vida! Porque ellas [...] de repente están tan encerradas en su mundo que no ven nada, en sus cuatro paredes. Entonces llega uno con otra mentalidad y les empiezas a hablar de que afuera hay todo un mundo que las está esperando y que es sólo decisión de ellas salir y vivir. Y que tienen derecho a vivir en paz, tranquilas y desarrollarse (facilitadora estable Fundación Prodemu).

Esto también permite entender la limitada o nula capacidad de dichas monitoras de reconocerse en situación de subordinación de género al igual que las participantes, y viceversa. Aquí influyen las diferencias de poder implícitas en la estructura jerárquica de las instancias formativas y de aula tradicional, y otras basadas en la edad y la clase, las que demarcan distancia entre las mujeres que se congregan en el taller.

Mientras tanto, las relaciones entre las participantes están condicionadas por el habitar del territorio en común, que las hace conocerse y frecuentarse previamente al taller en calidad de vecinas. Varias mujeres declararon que a 
pesar de esa condición, no mantienen relaciones de confianza ni conversan entre ellas sobre los temas del Taller de Desarrollo Personal, logrando descubrir otras facetas de sus vecinas a lo largo de las sesiones.

Yo creo que esa es la que más me hizo reír... es que es como tan... yo siempre he conversado con ella po, pero igual yo nunca pensé que ella era así tan como que llega y dice... (Carla, 22 años).

Es entretenido, y uno como que dialoga más con las otras personas. Porque no, yo acá... ¡copucheo no más! Porque yo acá, no soy muy sociable po; o sea, yo aquí en la casa salgo aquí a comprar y me vengo al tiro. Entonces así como que sirve más para tener tu espacio (Selena, 22 años).

En este grupo se pudo impulsar un proceso de construcción de sororidad con miras a vencer la enemistad histórica, poniendo unos primeros cimientos para otra forma de relación entre el grupo de mujeres, en tanto que tuvieron la posibilidad de conocer a sus vecinas en otro contexto, descubrir que ocupan un rol social similar y que, en ese sentido, comparten vivencias:

Esta soledad específicamente femenina sólo puede ser subvertida por la posibilidad de encontrarse con la otra, de mirar a la otra convertida en mí, como camino necesario para constituir a la mujer sujeto que reconozca, a la vez, la semejanza con otras y la diferencia con los hombres, y desde ese reconocimiento pueda lograr identificaciones comunes (Lagarde, I 992: 3).

El factor de clase en común también potencia esta unidad, dado que todas viven en un mismo territorio, con realidad material y económica similar.

La mía, la tuya, la nuestra: La construcción de la conciencia de género

Este apartado reúne aquellos momentos donde las mujeres declararon sobre el proceso de concienciación de género del taller, refiriéndose no sólo a lo sucedido en él, sino relatando también vivencias personales de concienciación de género, además de remitirse a sus propias definiciones de «tener conciencia». Aquí es importante considerar que:

Es difícil distinguir lo que llevó a las mujeres a estos grupos de lo que ocurrió cuando ya estaban en ellos. Igual que en cualquier interacción so- 
cial compleja [...], muchas veces es difícil separar los presupuestos de los descubrimientos [...]. ¿De dónde viene la conciencia? Es difícil distribuir la eficacia de la concienciación entre el propio proceso y las mujeres que deciden participar de él (MacKinnon, I995: I 58 ).

Así, con la dificultad de atribuir la concienciación de género a lo ocurrido dentro o fuera del taller, conocer las experiencias de las entrevistadas frente a esa instancia contribuye a reflexionar sobre los límites de la concienciación de género, tanto en procesos formativos como en la vida personal. Las categorías emergentes de «concienciación personal» $\mathrm{y}$ «definición de concienciación» evidencian su calidad no monolítica, reafirmando que «no podemos aceptar la concepción mecánica de la conciencia, que la ve como algo vacío que debe ser llenado, factor que aparece además como uno de los fundamentos implícitos en la visión bancaria criticada» (Freire, 2003: 84), pues en ella se conjugan múltiples factores y sobre todo experiencias de las trayectorias de vida de cada mujer.

\section{¿Qué es la creación de la conciencia?}

En palabras de las funcionarias y monitoras, la creación de la conciencia de género es un momento de reflexión crítica relativa a la situación de la mujer tradicional, que recluida en su casa, se dedica al cuidado de otros y otras, sin ser para sí (Freire, 2003). Declaran que el deber de sus labores es mostrar a las mujeres otras posibilidades y expectativas de vida, contrapuestas a la explotación doméstica, que diagnostican como tónica general en las circunstancias de los grupos de mujeres con los que trabajan.

$\mathrm{Y}$ a veces como que nadie les ha dicho eso, entonces creen que el mundo son las cuatro paredes y el marido es el que manda. Claro, abrirle un poco los ojos, es la idea (facilitadora estable Fundación Prodemu).

De las funcionarias vinculadas al taller de Pishuinco, sólo la directora provincial de la Fundación se refirió con más énfasis a la no ocupación del mundo público como una desventaja para las mujeres —incluida ella misma- en lugar de decretar insufrible la vida doméstica y el mundo privado.

Iba reafirmando mis ganas de seguir, de trabajar y dedicarme nada más que a preparar o a trabajar con mujeres y abrirles, darles esa oportunidad 
de que... o motivarlas para que ellas empiecen a mirar más lejos y empiecen a ver que había un mundo fuera que estaba también para hombres y mujeres, pero que no estaba siendo utilizado por nosotras (directora provincial Fundación Prodemu).

Esta discusión se relaciona con una conversación sostenida por el equipo provincial de la Fundación en una de sus reuniones:

El debate recae en las distintas opciones y formas de vida que puede tener una mujer, a partir de lo conversado frente a la posibilidad de trabajar con campesinas, mujeres mapuche, mujeres privadas de libertad y el reconocimiento de sus distintas realidades. Entonces una GFC [Gestora de Formación y Capacitación] declara: «El problema no es que sean dueñas de casa, sino que lo elijan, que no sea porque no les quedó otra». A lo que las demás asienten (Diario de Campo, reuniones de equipo Fundación Prodemu).

Para estas funcionarias, la concienciación se produce y trabaja intensamente en los talleres, donde interesa que las mujeres reconozcan problemáticas personales como colectivas, siendo las facilitadoras agentes clave en la propulsión de las reflexiones en torno a la desigualdad social entre hombres y mujeres. El concepto de empoderamiento fue muy mencionado como meta última, definiéndolo de diferentes formas, entre las que se cuentan la toma de decisiones autónomas, elevar el autoestima y la autoconfianza en las propias capacidades, reconocerse valiosas, etcétera; arguyendo que el empoderamiento es un medio para emprender posteriormente en actividades sociales o en el mundo público, como la búsqueda de trabajo remunerado, la ocupación de espacios de participación social, etcétera.

Para las participantes, la concienciación de género es un espacio de autoconocimiento propio y de sus demás compañeras, que requiere darse cuenta de su situación como mujeres, reflexionar sobre ella y revisar sus posibilidades de mejoramiento. Declararon que el hablar sobre conceptos como género o desigualdad era algo ajeno antes del taller, y más aún el intentar situarlos o aplicarlos a sus vidas, expresando también que muy rara vez cuestionaban su situación y contexto, en parte por la falta de confianza o tiempo con otras mujeres para hablar del tema.

Yo me sentí feliz, yo me sentí escuchada. Y me sentí con ganas de participar, porque generalmente en las agrupaciones no se dan estos temas de 
conversación. Por ejemplo, uno cuando se junta con amigas se habla, que sé yo po, de la novela que está viendo, del tiempo, de los hijos, y no habla estos temas tan íntimos po [...] y uno por no compartir sus problemas, sus cosas, no las conversa, se las calla (Maribel, 45 años).

En ese sentido, también mencionaron que las facilitadoras cumplen un papel determinante como catalizadoras del proceso de concienciación, atribuyéndolo en gran parte a lo que ellas les entregaron en el taller.

\section{La mía, la tuya: Concienciación personal}

Las funcionarias y facilitadoras identificaron experiencias que han abierto sus ojos frente a la subordinación de género en su vida diaria, varias de ellas relativas a la tensión entre mundo privado y mundo público: dificultades o discriminación en el ingreso a la vida laboral, dificultades en la compatibilización de la vida familiar con el trabajo, etcétera.

Estudié diseño gráfico, me metí a la universidad, salí, y después ya con mi segundo hijo, dije, ya lo voy a criar yo porque al primero lo crió la sala cuna, entonces el segundo lo iba a criar yo (ríe). Me fui a mi casa y estuve como 6 años en la casa, iy ya no quería más! Y así fue como entré a Prodemu, buscando... y en la casa como que igual fue como un terremoto... (facilitadora estable Fundación Prodemu).

Sus historias de superación de opresión las entusiasman a invitar a otras mujeres a llevar a cabo un proceso igual al que ellas experimentaron en el pasado, y otras situaciones tienen que ver con su experiencia previa en el trabajo con mujeres; clave para su desempeño en Prodemu y el despliegue de los talleres.

En conversaciones que he tenido en temas familiares también que me han dicho, "pucha, que bueno que tú saliste adelante, que no te quedaste en la casa y todo». Por eso te digo, es lindo el trabajo y a la vez uno también va aprendiendo, o sea, una cosa que la reconocen a uno por un tema de cómo salió adelante, por las expectativas que uno tiene como persona, y también por el tema profesional y a la vez el tema de conocer que hay otras realidades de vida de cada mujer (monitora externa Fundación Prodemu). 
Para las participantes, la conciencia de género está relacionada principalmente con vivencias derivadas de la interacción con sus parejas o maridos. Una serie de hechos cotidianos vinculados a las relaciones de pareja las han hecho percatarse de sus desventajas, entre las que cuentan explotación doméstica, emocional y sexual; discriminación de género, violencia intrafamiliar. Relacionan el tener conciencia con hacer respetar sus necesidades, quererse a sí mismas, considerarse en igualdad de derechos y condiciones con sus parejas y maridos, poner en valor su labor como dueñas de casa, informarse para mejorar su situación de vida, etcétera. Varias visibilizan el proceso de concienciación como algo vigente, ya sea porque están experimentando situaciones que ponen en jaque su condición social de mujeres, o porque están poniendo en práctica lo aprendido gracias a la concienciación proveniente del taller, vinculándose ambos momentos.

Yo creo que ahí el taller me ayudó a decidirme, a decir «ya no más» y separarme, porque igual uno decía ya pero ¿y el qué dirán? Pero ahora ya no ya. Yo dije no po, por qué, si yo puedo trabajar, yo puedo salir adelante, yo siempre lo he hecho (Carla, 22 años).

\section{La nuestra: Concienciación de género en talleres para mujeres}

En general, las funcionarias se mostraron satisfechas frente al trabajo de conciencia de género del Taller de Desarrollo Personal, por la introducción de conocimientos y espacios para la reflexión en un grupo de mujeres donde estas instancias eran inexistentes. Otro argumento favorable de las ejecutoras fue el de la utilidad del taller como un punto de partida para las mujeres, donde la revisión de la posición propia, el autoestima y el conocimiento de sus derechos se consideran claves para fines posteriores, defendiendo la necesidad de que las participantes pasaran revista a su situación de vida, expectativas, metas, etcétera, antes de agruparse, organizarse o emprender actividades fuera del hogar, como trabajar o capacitarse. Nuevamente, la concienciación es compartida por el grupo de mujeres y no por las funcionarias, quienes se ven fuera del proceso o distantes porque son las impulsoras de la concienciación de otras.

Dentro de los resultados positivos de lo realizado en el taller, identificaron el surgimiento de un espacio que forjó capacidad crítica y reflexiva sobre la situación de género de las mujeres, vinculada a su contexto y territorio. 
Las complejidades del trabajo se relacionaron con la continuidad del proceso, debido al fracaso de la intención de organizar a las mujeres mediante una agrupación.

Las participantes que valoraron positivamente el taller destacaron la posibilidad de expresarse en grupo, de hablar de sus problemas cotidianos, de informarse sobre temas de mujeres e incorporar nuevos conceptos a su vocabulario:

Es bueno que uno tenga un refuerzo, yo lo miro como un refuerzo, lo miro de esa manera. Yo digo, más que el apoyo monetario o en cosas, el apoyo eh... sicológico más que nada. Entonces es bueno. Ya una no está sin saber nada (Melissa, 30 años).

Me ha enseñado harto el taller. Bastante, bastante. Porque igual una aprende cosas nuevas po, a tomar decisiones, a valorizarse más. Igual una nunca termina como de quererse harto, harto, pero ahora sí. La autoestima te sube, todo eso... porque incluso yo ahora hasta opino en el taller po, o sea, y antes nada. Y ahora opino con las chicas entonces ya como que yo me voy desahogando, es muy bueno, a mí me gusta el taller (Carla, 22 años).

Esta valoración de los programas y políticas que se enfocan en «el poder intrínseco» (Sen, I997) por sobre el poder económico, y demuestran que la información es clave para el empoderamiento y es apreciada por las personas:

Controlar la información es una clásica táctica de los poderosos. Sirve para marginar a los que no tienen poder al estatus de objetos o beneficiarios, en lugar de ser agentes activos que el empoderamiento genera. Los gobiernos pueden hacer mucho para hacer accesible la información en diversos aspectos, abarcando desde la gestión del desarrollo hasta los derechos humanos (Sen, I997).

Asimismo, relacionaron los aprendizajes del taller con el aumento de autoestima, seguridad personal y autoconocimiento. Refirieron al proceso de concienciación como algo simultáneamente individual y colectivo, que incluye los aprendizajes adquiridos con las monitoras y con las experiencias y opiniones de las otras participantes; ya que a partir de las desafortunadas historias de subordinación femenina relatadas por otras vecinas, declararon haber obtenido aprendizajes. 
La clase pasada cuando una señora nos contaba su historia de cuando ella estuvo casada, que su marido le cerraba las ventanas hasta con frazadas pa que ella no mire para afuera. Sí, y nos decía que una vez él la intentó de matar y como que yo pensaba y yo decía [...] chuta, de verdad que yo dije no po, y porqué tengo por qué estar con alguien que no me quiere o que yo ya... ya no es lo mismo como antes, entonces yo ya no (Carla, 22 años).

No obstante, también hubo opiniones divergentes de participantes que dijeron no haber adquirido conocimientos o que no les fueron de utilidad. Una mujer recalcó que considera positivo el esfuerzo realizado en la prevención de la violencia contra las mujeres, pero le pareció que se hace con demasiada insistencia, arguyendo que ella ya manejaba éste y otros temas relacionados.

Es que al principio igual los temas no eran muy buenos. Como cosas comunes que uno sabía po. Y ahora ya está mejor [...]. Bueno que apoyen a las mujeres que golpean, pero... igual son muy catetes sí [ríe] (Silvina, 23 años).

Otra participante negó que hablar de desigualdad de género en el taller le fuera útil actualmente, dado que no le afectaba porque se desempeñaba como madre y dueña de casa, y sólo se relacionaba con su padre como figura masculina.

Yo tampoco puedo ver eso de los tipos de género porque, como yo estoy todo el día aquí en la casa, la única [figura] masculina que vemos es mi papá po [...]. Ahora, fuera diferente, si yo estuviera afuera trabajando... me relacionaría más con hombres, en el trabajo y cosas así... (Selena, 22 años).

Pese a la claridad con que estas mujeres otorgaron sus testimonios, varias de ellas evidenciaron prácticas de reproducción de la desigualdad de género, al explayarse en las entrevistas sobre sus relaciones interpersonales y vivencias cotidianas. Algunas sostenían matrimonios que no las tienen satisfechas, otras se resignan a que la responsabilidad de criar a sus hijos e hijas recaiga sólo en ellas, varias reproducen la crianza sexista, etcétera. La mayor congruencia entre declaraciones y prácticas la expresaron las más jóvenes del grupo, que aparentemente cuentan con mayores y mejores mecanismos para 
transformar aquellas condiciones de vida vinculadas con la subordinación de género.

\section{Conclusiones}

Este artículo sintetiza los resultados de una investigación que se propuso describir las experiencias de las mujeres involucradas en el Taller de Desarrollo Personal realizado en Pishuinco frente al trabajo de conciencia de género que se trabajó en él, observándose que dicho proceso es complejo y trasciende los límites de la propuesta formativa de los Talleres para Mujeres.

Conocer y reconocer la diversidad de trayectorias de las mujeres y los múltiples puntos de partida existentes ante el proceso de concienciación, permite dimensionar la variedad de realidades y procesos personales que se conjugaron en un mismo espacio y en la misma aula. Las expectativas frente al taller, tanto de facilitadoras como de participantes, se relacionan intensamente con esas trayectorias de vida y puntos de partida personales, y condicionan tanto las prácticas e interacciones — cómo se perciben a sí mismas, a las otras y cómo se relacionan entre sí-, así como las conclusiones y resultados que obtienen de esta instancia, es decir, cómo entienden y evalúan el proceso de concienciación individual y colectivo.

Además, importa destacar que el desarrollo de la conciencia de género no necesariamente desemboca en prácticas emancipatorias contra la desigualdad, pues la sujeción de las mujeres a la subordinación depende también de condiciones materiales y/o estructurales difíciles de subvertir, como la dependencia económica o un bajo nivel de escolaridad.

Las distintas aristas expuestas por las mujeres que colaboraron en esta investigación denotan que el proceso de concienciación se compone de diversas experiencias de subordinación, personales y/o colectivas, que debido a las limitaciones de género relacionadas con el confinamiento al espacio privado y a las relaciones de enemistad entre congéneres, son socialmente inhibidas en grupos de pares. Es en ese sentido que reaparece la mayor virtud del taller, el cual fue de provecho para muchas de sus participantes que no contaban con alguna experiencia similar. Metodológicamente hablando, la fortaleza de los talleres reside en su calidad de instancia colectiva.

La recopilación de estas experiencias invita a repensar las relaciones entre mujeres y los espacios grupales dispuestos para ello, pues si bien la estructura institucional que ampara al Taller de Desarrollo Personal de Pishuinco es 
condicionante de los repertorios de prácticas, interacciones y metodologías imperantes que están en línea con las políticas públicas del Estado, también se amparan en una cultura de relaciones entre mujeres, intersectadas por las variantes de clase, territorio, estatus social, etcétera. Allí, ha sido el feminismo poscolonial el que ha entregado luces respecto a esas complejidades.

Para efectos de la investigación, el enfoque de la educación popular, la pedagogía feminista y la experiencia de los grupos de concienciación del feminismo de la segunda ola, contribuyeron en la lectura crítica de esta instancia, dado que al remitir a la dimensión política del acto pedagógico respaldan el relevamiento de las voces de aquellas mujeres que estuvieron envueltas en el proceso, sus trayectorias de vida, expectativas, opiniones y percepciones frente a lo acontecido.

Finalmente, es menester dar crédito a la metodología utilizada que, basada en el método etnográfico, responde al desentrañamiento del Taller de Desarrollo Personal de Pishuinco por medio de la triangulación de la información desprendida de sus diferentes elementos constitutivos, con la articulación crítica y analítica de ellos, y manteniendo el énfasis en la información de primera fuente, aquella que emana de las protagonistas de la instancia. En ese sentido, también importa destacar la experiencia etnográfica, donde la relación directa con las mujeres implicadas en el taller, el exhaustivo trabajo de campo y la construcción de confianzas permitieron realizar un extenso trabajo de análisis y posicionamiento crítico que se hace tangible en la presente síntesis de resultados.

\section{Referencias}

Barragán, Rossana y Fernanda Wanderley (2009). «Etnografías del Estado en América Latina». Íconos, 34: 2I-25. Disponible en: http://www.redalyc. org/articulo.oa? $\mathrm{id}=509 \mathrm{II} 338002$.

Canales, Manuel (2006). Metodologías de investigación social. Introducción a los oficios. Santiago de Chile: Lom.

-. (2013). Investigación social. Lenguajes del diseño. Santiago de Chile: Lom. Cook, Rebecca (I993). «Women's International Human Rights Law: The Way Forward». Human Rights Quarterly, I 5 (2): 230-26I. Disponible en https://www.jstor.org/stable/762538?seq=I\#page_scan_tab_contents.

Freire, Paulo (2003). Pedagogía del oprimido. Buenos Aires: Siglo XXI.

-. (2005). Pedagogía de la esperanza. Un reencuentro con la pedagogía del oprimido. Buenos Aires: Siglo XXI. 
Gúber, Rosana (20I I). La etnografía. Método, campo y reflexividad. Buenos Aires: Siglo XXI.

Haraway, Donna (I995). Ciencia, cyborgs y mujeres: La reinvención de la naturaleza. Valencia: Cátedra.

Korol, Claudia (ed.) (2007). Hacia una pedagogía feminista. Buenos Aires: El Colectivo, América Libre.

Lagarde, Marcela (I992). «Enemistad y sororidad. Hacia una nueva cultura feminista». Isis Internacional, I7. Disponible en: http://e-mujeres.net/sites/ default/files/Enemistad\% 20y\% 2osororidad.pdf.

Maceira, Luz (2007). «Una propuesta de pedagogía feminista: Teorizar y construir desde el género, la pedagogía y las prácticas feministas». Ponencia presentada en el I Coloquio Nacional Género en Educación. Universidad Pedagógica Nacional y Fundación para la Cultura del Maestro, AC. México, DF. Disponible en http://bit.ly/2iJDmJT.

MacKinnon, Catharine (1995). Hacia una teoría feminista del Estado. Madrid: Cátedra.

Montecino, Sonia (2014). Madres y huachos. Alegorías del mestizaje chileno. Santiago de Chile: Catalonia.

Narayan, Uma (2000). «Essence of culture and a sense of history: a feminist critique of cultural essentialism». En Sandra Harding y Uma Narayan (editoras), Decentering the Center. Philosophy for a Multicultural, Postcolonial and Feminist World (pp. 80-I 27). Indiana, USA: Hypatia Inc.

Pérez Bustos, Tania (20I0). «Aportes feministas a la educación popular: Entradas para repensar pedagógicamente la popularización de la ciencia y la tecnología». Educação e Pesquisa (Universidade de São Paulo), 36 (I): 243260. Disponible en http://www.scielo.br/pdf/ep/v36ni/ao4v36nI.pdf

Riquer, Florinda (1992). "La identidad femenina en la frontera entre la conciencia y la interacción social». En María Luisa Tarrés (editora), La voluntad de ser. Mujeres en los noventa (pp. 5I-64). México: El Colegio de México.

Scribano, Adrián (2007). El proceso de investigación social cualitativo. Buenos Aires: Prometeo.

Sen, Gita (1997). El empoderamiento como un enfoque a la pobreza. Quito: Biblioteca Asocam. Disponible en: http://www.asocam.org/biblioteca/ items/show/22I I.

Vasilachis de Gialdino, Irene (2006). Estrategias de investigación cualitativa. Barcelona: Gedisa. 
Weinstein, Marisa (I996). Estado, mujeres de sectores populares y ciudadanía. Santiago de Chile: Biblioteca Flacso. Disponible en: http://www.flacsoandes.edu.ec/libros/digital/45301.pdf.

Wilcox, Kathleen (I993). "La etnografía como una metodología y su aplicación al estudio de la escuela: una revisión». En Honorio Velasco, Francisco García y Ángel Díaz de Rada (editores), Lecturas de antropología para educadores (pp. 95-I26). Madrid: Trotta.

\section{Sobre la autora}

Bárbara Catalina López Castillo es Antropóloga de la Universidad Austral de Chile. Ha realizado desde sus estudios de pregrado una serie de pesquisas que vinculan las relaciones de género con otras esferas de la sociedad y la cultura, abordando la salud sexual y reproductiva en el mundo rural, la construcción de los roles de género en la educación formal y la relación de las mujeres con los servicios públicos y el Estado. Se ha desempeñado como facilitadora y etnógrafa en procesos de educación no formal para mujeres, jóvenes, niños y niñas, al alero de los enfoques de la educación popular y la pedagogía feminista. Actualmente realiza labores como Monitora Social del Centro de la Mujer de la Comuna de Carahue, Región de La Araucanía, donde contribuye a la atención de mujeres víctimas de violencia de pareja y a la prevención de la misma, manteniendo y afianzando vínculos con instancias académicas y de investigación social. Su correo electrónico es barbaracatalinalopez@gmail.com. 
